\title{
Kepuasan Pasien Imobilisasi dalam Pemenuhan Personal Hygiene Rumah Sakit Santa Elisabeth Medan
}

\author{
Pomarida Simbolon $^{1}$, Magda Siringo-ringo ${ }^{2}$ \\ STIKes Santa Elisabeth Medan ${ }^{1,2}$ \\ pomasps@yahoo.com ${ }^{1}$, magda_siringoringo@yahoo.com ${ }^{2}$
}

\begin{abstract}
ABSTRAK
Latar belakang: Personal hygiene merupakan perawatan diri manusia dalam memelihara kesehatannya untuk meningkatkan kenyamanan, kesehatan dan keamanan demi kesejahteraan fisik dan psikis terutama pada pasien imobilisasi. Setiap tindakan keperawatan, yang diberikan perawat harus memperhatikan kepuasan pasien karena merupakan salah satu indikator bagi pasien untuk mengetahui kualitas pelayanan melalui tingkat kepuasan.

Tujuan: Untuk mengetahui kepuasan pasien imobilisasi dalam pemenuhan personal hygiene yang dilakukan oleh perawat di Rumah Sakit Santa Elisabeth Medan.

Metode: Jenis penelitian adalah deskriptif, dengan metode penilaian menggunakan dimensi kepuasan. Populasi dalam penelitian berjumlah 120 orang dengan jumlah sampel penelitian 30 orang dengan menggunakan purposive sampling. Pengumpulan data dengan menggunakan kuesioner.

Hasil: Hasil penelitian menunjukan tingkat kepuasan pasien pada dimensi tangible (kenyataan) $63,3 \%$, emphaty (empati) 46,7\%, reliability (keandalan) 50,0\%, responsivenness (daya tanggap) 53,3\%, sedangkan dimensi assurance (jaminan) berada pada kategori puas yaitu $43,3 \%$.

Kesimpulan: Pasien sangat puas terhadap pelayanan personal hygiene, terlihat dari perhitungan setiap dimensi. Diharapkan kepada perawat agar memberikan pelayanan yang lebih baik lagi terutama kesan pertama masuk pasien terhadap pelayanan keperawatan yang diberikan sehingga hasil kepuasan lebih meningkat lagi.
\end{abstract}

Kata kunci: Kepuasan pasien, Imobilisasi, Personal Hygiene

\begin{abstract}
Background:Personal hygiene is a human self-care in maintaining health to improve comfort, health and safety for the physical and psychological well-being, especially in immobilized patients. Each nursing action, given by the nurse must pay attention to patient's satisfaction because it is one of the indicator for patient to know the quality of service through level of satisfaction.

Objective:The purpose of research to know patient satisfaction immobilization in fulfillment of personal hygiene done by nurse at Santa Elisabeth MedanHospital.

Methods: The type of research is descriptive, with assessment method using dimension of satisfaction. The population in the study amounted to 120 people with the number of research samples of 30 people by using purposive sampling. Data collection using questionnaire.

Results: Patients satisfaction regarding tangible (reality) 63,3\%, empathy 46,7\%, reliability 50,0\%, responsivenness 53,3\%, while assurance dimension (guarantee) is in satisfied category that is 43,3\%.

Conclusion: showed that very satisfied can be seen from the calculation of each dimension. It is expected to nurse to give better service again to first impression to enter patient to nursing service given so that result of satisfaction even more increase
\end{abstract}

Key words: Patient Satisfaction, Immobilization, Personal Hygiene 


\section{PENDAHULUAN}

\begin{tabular}{lcr}
\multicolumn{2}{c}{ Personal hygiene merupakan } \\
perawatan diri manusia & dalam \\
memelihara & kesehatannya & untuk
\end{tabular} meningkatkan kenyamanan, kesehatan dan keamanan. Karena mengalami gangguan kesehatan, maka kemungkinan ada satu atau beberapa kebutuhan dasar pasien akan terganggu. Terutama pada bagian kebutuhan fisik harus dipenuhi lebih dahulu karena merupakan kebutuhan personal hygiene. Hal yang harus di miliki perawat baik dari segi kemampuan atau cara dalam pemenuhan kebutuhan dasar pasien, dengan memantau dan mengikuti perkembangan kemampuan pasien dalam melaksanakan aktifitas kehidupan sehari-hari untuk memenuhi kebutuhan dasar terutama pasien imobilisasi (Susanti, 2013).

Dalam pemenuhan kesehatan klien ada beberapa jenis pelayanan pada klien yaitu self care/perawatan mandiri, memerlukan waktu 1-2 jam/hari: kebersihan diri seperti mandi, ganti pakaian sendiri, makan dan minum dilakukannya sendiri, ambulasi dengan pengawasan. Intermediet care/perawatan partial, memerlukan waktu 3-4 jam/hari: kebersihan diri bantu, makan minum dibantu, observasi tanda-tanda vital setiap 4 jam, ambulasi di bantu, pengobatan dengan injeksi, klien dengan kateter urine, pemasukan dan pengeluaran dicatat, klien dengan infus. Intensif care/total care, memerlukan waktu 5-6 jam/hari:semua kebutuhan klien dibantu, perubahan posisi setiap 2 jam dengan bantuan, observasi tanda-tanda vital setiap 2 jam, makan dan minum melalui selang lambung, pengobatan intravena, dilakukan suction, gelisah/diorientasi (Rachmawati, 2008)

Pelayanan di rumah sakit dapat diketahui dari aktivitas dan efektivitas pelayanan yaitu pada pasien yang tidak mampu memenuhi kebutuhannya seperti pasien post operasi cenderung mengalami imobilisasi karena pada hari pertama post operasi tidak dianjurkan duduk, pasien masih mengalami nyeri, karena timbulnya nyeri, keterbatasan gerak, maka semua bentuk kegiatan menjadi berkurang termasuk dalam kemampuan pasien untuk pelaksanaan pemenuhan personal higiene, sehingga kebutuhan pasien perlu banyak dibantu oleh perawat atau keluarga, sehingga perlu dipertimbangkan toleransi pasien melakukan aktivitas. Setelah post operasi pasien harus di imobilisasi atau dipertahankan dalam posisi dan kesejajaran yang benar. Masa penyembuhan atau mobilisasi biasanya tergantung dari jenis operasi dan tingkat keparahan penyakit tersebut, tetapi pada usia lanjut atau status kesehatan yang buruk mungkin diperlukan waktu yang lebih lama dan membutuhkan pemenuhan personal hygiene (Brunner \& Suddarth, 2002).

Berdasarkan hasil penelitian Heni (2011) kepuasan pasien pada perawat maupun pelayanan personal hygiene di RS Prikasih Jakarta Selatan. Pasien paling banyak menyatakan setuju yaitu 18 orang $(60,0 \%)$, amat setuju 9 orang $(30 \%)$, kurang setuju 1 orang $(6,7 \%)$ terhadap kepuasan pasien dalam pelayanan personal hygiene. Hasil ini menunjukkan bahwa sebenarnya masih ada pasien yang memiliki personal hygiene rendah akibat dari peran perawat masih kurang dalam pelaksanaan personal hygienepada pasien.

Pasien imobilisasi memerlukan bantuan dalam memenuhi kebutuhan fisik, karena pasien tidak mampu memenuhi kebutuhannya sendiri. Imobilisasi didefinisikan sebagai tingkat aktivitas yang kurang dari mobilitas optimal. Mobilitas sendiri adalah pergerakan yang memberikan kebebasandankemandirian bagi seseorang (Heni, 2011)

Walaupun jenis aktivitas berubah sepanjang kehidupan manusia, mobilitas adalahpusat untuk berpartisipasi dalam dan menikmati kehidupan. Ada beberapapasien yang harus tinggal di tempat tidur untuk periode waktu lama. Imobilisasi yang lama berdampak negatif yaitu mempengaruhi kulit secara langsung dan beberapa organ tubuh lainnya.Pasien imobilisasi sangat membutuhkan bantuan dalam kebutuhan merawat diri, sangat membutuhkan bantuan dalam kebutuhan merawat diri, maka sebagai perawat dalam memberikan tindakanpersonal hygiene, perawat harus mempunyai keinginan agar hasil yang dicapai memuaskan pada pasien 
imobilisasi di ruangan bedah terutama untuk meningkatkan kesehatan, kenyamanan, dankepuasan pasien(Heni, 2011).

Kepuasan pasien adalah tingkat perasaan seseorang setelah membandingkan kinerja (atau hasil) yang dia rasakan dibanding dengan harapannya. Karena itu pasien tidak akan puas apabila pasien mempunyai persepsi bahwa harapannya belum terpenuhi. Pasien akan merasa puas jika persepsinya sama atau lebih dari yang diharapkan (Pohan, 2006)

Berdasarkan data pada rekam medis Rumah Sakit Santa Elisabeth Medan khususnya di Ruang Santa Maria dan Santa Marta terhitung mulai bulan Januari hingga Agustus 2016 jumlah pasien post operasi yang dirawat di Ruang Santa Maria dan Santa Marta 120 orang. Alasan pengambilan lokasi karena belum pernah melaksanakan penelitian tentang kepuasan pasien immobilisasi.

\section{METODE}

Jenis penelitian ini menggunakan deskriptif. Penelitian ini bertujuan untuk mengetahui kepuasan pasien imobilisasi dalam pemenuhan personal hygiene oleh perawat di Ruangan Bedah Rumah Sakit Santa Elisabeth Medan 2017.

Populasi dalam penelitian adalah pasien imobilisasi yang ada di Ruangan Bedah Rumah Sakit Santa Elisabeth Medan berjumlah 120 orang/tahun khusus pasien imobilisasi post operasi. Rumus pengambilan sampel yaitu $\mathrm{n}=\mathrm{N} \mathrm{x}$ $20-25 \%$ (Arikunto, 2010). Jadi Jadi, $\mathrm{n}=124$ x $24 \%=29,76$ orang $=30$ orang. Jumlah sampel dalam penelitian 30 orang. Teknik sampling yang digunakan yaitu purposive sampling agar sesuai dengan yang dikehendaki peneliti.

Pengumpulan data yang dilakukan dalam penelitian adalah dengan menggunakan data primer dan sekunder. Data primer pada penelitian diperoleh secara langsung dari reponden/subjek penelitian dengan cara membagikan kuesioner kepada responden sedangkan data sekunder pada penelitian diperoleh secara tidak langsung pada bagian rekam medis. Analisa data dilakukan terhadap kuesioner yaitu dengan menggunakan analisis univariat untuk menjelaskan variabel penelitian.

\section{HASIL PENELITIAN DAN PEMBAHASAN}

1. Kepuasan Pasien Imobilisasi berdasarkan Tangible (kenyataan)

Hasil penelitian diperoleh kepuasan pasien berdasarkan tangible (kenyataan)mayoritas sangat puas sebanyak 19 orang (63,3\%). Hal ini dapat terjadi karena dalam melakukan asuhan keperawatan perawat telah menerapkan asuhan keperawatan sesuai dengan standar Operasional yang berlaku dan dengan menggunakan fasilitas dan peralatan yang sesuai dengan kebutuhan pasien. Pasien merasa sangat puas menyatakan bahwa perawat kerap meminta persetujuan pasien sebelum melakukan tindakan, penampilan bersih dan rapi, menjaga privasi pasien, berkomunikasi pada pasien saat melakukan tindakan pada pasien, dan mengevaluasi kenyamanan pasien serta menerapkan komunikasi teraupeutik baik terhadap pasien.

Menurut Parasuraman dalam Nursalam (2014) bahwa tangible merupakan berupa penampilan fasilitas fisik, dan peralatan materi komunikasi yang menarik. Bentuk aktualiasasi nyata secara fisik dapat terlihat atau digunakan oleh pegawai sesuai dengan penggunaan dan pemanfaatannya yang dapat dirasakan membantu pelayanan yang diterima oleh orang yang menginginkan pelayanan, sehingga puas atau pelayanan dirasakan yang sekaligus menunjukkan prestasi kerja atau pemberian pelayanan yang diberikan.

Bentuk pelayanan bukti fisik biasanya berupa sarana dan prasarana yang tersedia dalam pelayanan, teknologi pelayanan yang digunakan, performance pemberi pelayanan yang sesuai dengan karakteristik pelayanan yang diberikan dalam menunjukkan prestasi kerja yang dapat diberikan dalam bentuk pelayanan fisik yang dapat dilihat.

Tabel 1. Distribusi Frekuensi Kepuasan Pasien Imobilisasi berdasarkan Tangible (kenyataan) tahun 2017

\begin{tabular}{llc}
\hline Tangible & F & $\%$ \\
\hline Tidak puas & 1 & 3,3 \\
\hline
\end{tabular}


Tabel 1. (lanjutan) Distribusi Frekuensi Kepuasan Pasien Imobilisasi berdasarkan Tangible (kenyataan) tahun 2017

\begin{tabular}{lcc}
\hline Tangible & F & $\%$ \\
\hline Cukup puas & 2 & 6,7 \\
Puas & 8 & 26,7 \\
Sangat puas & 19 & 63,3 \\
\hline Total & 30 & 100 \\
\hline
\end{tabular}

\section{Kepuasan Pasien Imobilisasi} berdasarkan Emphaty (empati)

Hasil penelitian diperoleh kepuasan berdasarkan emphaty (empati)di Ruangan Bedah Rumah Sakit Santa Elisabeth Medan 2017 yaitu mayoritas sangat puas sebanyak 14 orang $(46,7 \%)$ hal ini karena dalam melakukan tindakan pemenuhan personal hygiene perawat telah melakukan tindakan sesuai dengan standar yang berlaku dan melakukan komunikasi yang baik dan memiliki rasa kepedulian yang tinggi terhadap pasien. Pasien yang mendapatkan perawatan seperti ini merasa sangat nyaman dan dapat melihat ketulusan (empati) atas tindakan yang dilakukan oleh perawat. Responden menyatakan sangat puas terhadap tindakan yang dilakukan oleh perawat dalam memberikan pelayanan pemenuhan personal hygiene secara adil tanpa memandang status sosial ekonomi pasien, perawat memberi kesempatan pada pasien untuk bertanya atas keingintahuan pasien, dan tindakan yang dilakukan perawat sesuai dengan keinginan pasien, serta perawat bersikap ramah dan sopan pada pasien.

Hasil penelitian ini sejalan Suardana (2013) dapat disimpulkan bahwa perawat memberikan kesempatan mengungkapkan kebiasaan keluarga yang bertentangan dengan aturan Rumah sakit dan perawat memandikan pasien secara adil tanpa memandang status sosial ekonomis.

Hal ini didukung oleh Nursalam (2014) bahwa emphaty (empati) merupakan ketersediaan karyawan untuk memberikan perhatian secara pribadi pada pasien. Setiap kegiatan atau aktivitas pelayanan memerlukan daya pemahaman dan pengertian dalam kebersamaan kepentingan terhadap suatu hal yang berkaitan dengan pelayanan. Pelayanan akan berjalan dengan lancar dan berkualitas apabila setiap pihak yang berkepentingan dalam pelayanan memiliki adanya rasa empati dalam menyelesaikan atau memiliki komitmen dalam pelayanan.

Tabel 2. Distribusi Frekuensi Kepuasan Pasien Imobilisasi berdasarkan Emphaty (empati)Tahun 2017

\begin{tabular}{lcc}
\hline Emphaty & F & \% \\
\hline Tidak puas & 2 & 6,6 \\
Cukup puas & 6 & 20,0 \\
Puas & 8 & 26,7 \\
Sangat puas & 14 & 46,7 \\
\hline Total & 30 & 100,0 \\
\hline
\end{tabular}

\section{Kepuasan Pasien Imobilisasi} berdasarkan Reliability(keandalan)

Hasil penelitian diperoleh kepuasan berdasarkan reliability (keandalan)di Ruangan Bedah Rumah Sakit Santa Elisabeth Medan yaitu mayoritas berada pada ketegori sangat puas sebanyak 15 orang $(50,0 \%)$ karena responden menerima tindakan sesuai dengan prosedur perlakuan yang baik, mendapat informasi sebelum tindakan personal hygiene, kebersihan kulit yang tahu dengan waktu cepat dan tepat sebelum melakukan tindakan, perawat memandikan pasien tepat waktu, perawat menepati janjinya kepada pasien, perawat bekerja dengan cepat dan pasien merasa nyaman saat dilakukan perawatan kebersihan mulut, mata, hidung, dan telinga pasien sehingga pasien merasa puas atas tindakan yang dilakukan secara nyata.

Hasil penelitian ini sejalan dengan Parinduri (2009) yang menyatakan bahwa dalam pemberian tindakan asuhan keperawatan perawat memberikan nyaman kepada pasien sehingga pasien puas terhadap tindakan perawat yang diberikan.

Menurut Susanti (2013) untuk dapat meningkatkan kualitas pelayanan tindakan keperawatan lebih khususnya terkait dengan pemenuhan kebutuhan personal hygiene perawat juga perlu diberikan pelatihan terkait personal hygiene sehingga meningkatkan motivasi perawat dalam pemenuhan kebutuhan kebersihan diri akan mampu mengatasisetiap permasalahan pasien. 
Tabel 3. Distribusi Frekuensi Kepuasan Pasien Imobilisasiberdasarkan Reliability (keandalan) Tahun 2017

\begin{tabular}{lcc}
\hline Reliability & F & \% \\
\hline Tidak puas & 4 & 13,3 \\
Cukup puas & 3 & 10,0 \\
Puas & 8 & 26,7 \\
Sangat puas & 15 & 50,0 \\
\hline Total & 30 & 100,0 \\
\hline
\end{tabular}

\section{Kepuasan Pasien Imobilisasi berdasarkan Assurance (jaminan)}

Hasil penelitian diperoleh kepuasan berdasarkan assurance (jaminan) di Ruangan Bedah Rumah Sakit Santa Elisabeth Medan yaitu mayoritas berada pada kategori puas sebanyak 13 orang $(43,3 \%)$. Hal ini dapat terjadi karena dalam melakukan asuhan keperawatan perawat melakukan tindakan sesuai dengan prosedur yang berlaku dan pasien merasa puas karena pelayanan perawat dapat memberikan rasa segar dan rasa aman dalam tindakan berkeramas, dalam melakukan asuhan keperawatan perawat menunjukkan etika yang baik dan memperhatikan kebutuhan dan hak pasien, perawat juga telah memiliki pengetahuan dalam menetapkan diagnosa pasien, sehingga mampu menjawabpertanyaan secara yakin dalam pemenuhan kebersihan diri pasien, perawat bersikap cekatan serta menghargai pasien, dan perawat melakukan tindakan dengan sikap yang meyakinkan sehingga pasien merasa aman dan nyaman. Hasil penelitian ini sejalan dengan Sandyarman (2013) yang menyatakan bahwa perawat selalu membiasakan melakukan tindakan personal hygiene sesuai dengan SOP dan terampil dalam memberikan layanan sehingga pasien merasa puas dan mendapatkan hasil yang maksimal.

Tabel 4. Distribusi Frekuensi Kepuasan Pasien Imobilisasi berdasarkan Assurance (jaminan) Tahun 2017

\begin{tabular}{lcc}
\hline Assurance & F & $\%$ \\
\hline Tidak puas & 2 & 6,7 \\
Cukup puas & 6 & 20,0 \\
Puas & 13 & 43,3 \\
Sangat puas & 9 & 30,0 \\
\hline Total & 30 & 100,0 \\
\hline
\end{tabular}

5. Kepuasan Pasien Imobilisasi berdasarkan Responsivenness (Daya Tanggap)

Hasil penelitian diperoleh kepuasan berdasarkan responsivenness (daya tanggap) di Ruangan Bedah Rumah Sakit Santa Elisabeth Medan yaitu mayoritas berada pada kategori sangat puas sebanyak 16 orang $(53,3 \%)$.

Hal ini dapat terjadi karena dalam melakukan asuhan keperawatan, perawat telah menerapkan asuhan keperawatan sesuai dengan standar yang berlaku dan dengan cepat dan tanggap serta dengan penuh tanggung jawab membantu pasien dalam memberikan pelayanan secara menyeluruh untuk menciptakan kepuasan pada pasien. Perawat juga selalu berupaya dengan cepat dan tanggap serta bersedia mendengarkan dan mengatasi keluhan pasien. Pasien yang merasa sangat puas menyatakan bahwa perawat memberikan penjelasan tujuan tindakan yang akan dilakukan, perawat memberi kesempatan menanyakan sesuatu terkait dengan kebersihan diri, perawat mengerjakan tindakan menjaga kebersihan diri dengan serius, perawat bersedia menanggapi keluhan pasien selama di rumah sakit terutama dalam kebersihan diri pasien, dan perawat selalu memperhatikan hak pasien dalam melakukan pemenuhan kebersihan diri pasien. Dalam melakukan asuhan keperawatan, perawat memberikan pelayanan secara cepat, mendengar dan mengatasi keluhan pasien sehingga pasien menyatakan sangat puas terhadap pelayanan yang dilakukan oleh perawat.

Berdasarkan hasil penelitian Pujiani (2008) tanggapan perawat pada keluhan pasien akan merasa dihargai dan diperhatikan dan segera menanggapinya, sehingga pasien merasa puas dengan pelayanan.

Hal ini sesuai dengan pernyataan Nursalam (2014) bahwa responsivennes (daya tanggap) merupakan kemauan karyawan untuk membantu pasien dalam memberikan pelayanan secara cepat dan tepat serta mendengarkan keluhan pasien dan setiap pegawai dalam memberikan bentuk-bentuk pelayanan, mengutamakan aspek pelayanan yang sangat memengaruhi perilaku orang yang 
mendapatkan pelayanan, sehingga diperlukan kemampuan daya tanggap dari pegawai untuk melayani masyarakat sesuai dengan tingkat penyerapan, pengertian ketidaksesuaian atas berbagai hal bentuk pelayanan yang tidak diketahuinya. Hal ini memerlukan penjelasan yang bijaksana, mendetail membina, mengarahkan dan membujuk agar menyikapi segala prosedur dan mekanisme kerja yang berlaku dalam suatu organisasi, sehingga bentuk pelayanan mendapat respon positif.

Tabel 5. Distribusi Frekuensi Kepuasan Pasien Imobilisasi berdasarkan Responsivenness (Daya Tanggap) Tahun 2017

\begin{tabular}{lcc}
\hline Responsivennes & F & $\%$ \\
\hline Tidak puas & 2 & 6,7 \\
Cukup puas & 8 & 26,7 \\
Puas & 4 & 13,3 \\
Sangat puas & 16 & 53,3 \\
\hline Total & 30 & 100,0 \\
\hline
\end{tabular}

\section{Kepuasan Pasien Imobilisasi Dalam Pemenuhan Personal Hygiene}

Hasil penelitian diperoleh kepuasan pasien imobilisasi dalam pemenuhan personal hygiene oleh perawatdi Ruangan Bedah Rumah Sakit Santa Elisabeth Medan yaitu mayoritas berada pada kategori sangat puas sebanyak 14 orang $(46,7 \%)$.

Tabel 6. Distribusi Frekuensi Kepuasan Pasien Imobilisasi Dalam Pemenuhan Personal Hygiene Tahun 2017

\begin{tabular}{lcc}
\hline Kepuasan & F & $\%$ \\
\hline Tidak puas & 2 & 6,7 \\
Cukup puas & 5 & 16,7 \\
Puas & 9 & 30,0 \\
Sangat puas & 14 & 46,7 \\
\hline Total & 30 & 100,0 \\
\hline
\end{tabular}

Hasil penelitian ini sejalan dengan Azhari (2013) yang menyatakan bahwa pasien puas dengan pelayanan yang diberikan melalui peningkatan personal hygiene.

Menurut Rachmania (2015) bahwa sikap dan pendekatan tenaga kesehatan kepada pasien, mutu pelayanan, prosedur administrasi, fasilitas-fasilitas yang disediakan.

Dalam penelitian ini perawat telah menerapkan asuhan keperawatan sesuai dengan standar yang berlaku, perawat juga telah melakukan komunikasi terapeutik yang baik dan perawat memperhatikan penampilan fisik saat berhadapan dengan pasien. Perawat memiliki rasa kepedulian yang tinggi terhadap pasien. Pasien yang mendapatkan perawatan dengan kepedulian yang tinggi merasa sangat nyaman dan dapat melihat ketulusan (empati) atas tindakan yang dilakukan oleh perawat. Perawat melakukan perawatan secara adil tanpa memandang status sosial ekonomi pasien, perawat memberi kesempatan pada pasien untuk bertanya atas keingintahuan pasien, dan tindakan yang dilakukan perawat sesuai dengan keinginan pasien, serta perawat bersikap ramah dan sopan pada pasien, memberikan informasi kepada pasien sebelum melakukan tindakan personal hygiene, perawat selalu ada di tempat bila pasien meminta bantuan, perawat menepati janjinya kepada pasien sehingga pasien merasa puas atas tindakan yang dilakukan secara nyata.

Dalam melakukan asuhan keperawatan menunjukkan etika yang baik dan memperhatikan kebutuhan dan hak pasien, perawat juga telah memiliki pengetahuan dalam menetapkan masalah pasien, sehingga perawat dapat melakukan pemenuhan personal hygiene, perawat bersikap cekatan serta menghargai pasien, dan perawat melakukan tindakan dengan sikap yang meyakinkan sehingga pasien merasa aman dan nyaman serta merasa mendapatkan jaminan pelayanan yang nyaman dan memuaskan, perawat telah menerapkan asuhan keperawatan sesuai dengan standar yang berlaku dan dengan cepat dan tanggap serta dengan penuh tanggung jawab membantu pasien dalam memberikan pelayanan secara menyeluruh untuk menciptakan kepuasan pada pasien dan tanggap serta bersedia mendengarkan dan mengatasi keluhan pasien sehingga pasien menyatakan sangat puas terhadap pemenuhan kebutuhannya.

\section{PENUTUP}

Kepuasan pasien imobilisasi berdasarkan tangible (kenyataan) dalam pemenuhan personal hygiene oleh 
perawat 19 responden $(63,3 \%)$ menyatakan merasa sangat puas, berdasarkan emphaty 14 responden $(46,7 \%)$ merasa sangat puas, berdasarkan reliability 15 responden (50\%) merasa sangat puas, berdasarkan assurance 13 responden $(43,3 \%)$ merasa puas, responsivenness 16 responden $(53,3 \%)$ merasa sangat puas.

Kepuasan pasien imobilisasi dalam pemenuhan personal hygiene oleh perawat 14 responden $(46,7 \%)$ merasa sangat puas.

\section{SARAN}

Bagi Rumah Sakit Santa Elisabeth Medan diharapkan kepada perawat agar memberikan pelayanan yang lebih baik lagi terutama kesan pertama masuk pasien terhadap pelayanan keperawatan yang diberikan sehingga hasil kepuasan lebih meningkat lagi.

\section{DAFTAR PUSTAKA}

Arikunto Suharsimi. 2010.Prosedur Penelitian Suatu Pendekatan Praktik. Jakarta: PT. Rhineka cipta.

Azhari. 2012. Hubungan Pelaksanaan Personal Hygiene Oleh Perawat Dan Tingkat Kepuasan Pasien Imobilisasi Di Lantai 5 Bedah Rumah Sakit Pusat Angakatan Darat Gatot Soebroto Jakarta Pusat. Diakses tanggal 10 Desember 2016

Heni, Dkk (2011) Pengaruh Intervensi Personal Higiene Terhadap Kepuasan Pasien Immobilisasi. Diakses tanggal 10 Desember 2016

Nursalam. $2014 . \quad$ Manajemen Keperawatan. Jakarta: Salemba medika.

Parinduri. 2009. Tingkat Kepuasan Pasien Imobilisasi Dalam Pemenuhan Pelaksanaan Personal Hygiene Oleh Perawat Di Rumah Sakit Haji Adam Malik Medan. Diakses pada tanggal 22 November 2016

Pohan Imbalo. 2006. Jaminan Mutu Layanan Kesehatan. Jakarta: EGC.

Rachmania (2015) Hubungan Mutu Pelayanan Kesehatan Dengan Kepuasan Pasien Rawat Inap Di Puskesmas Temon 1 Kulon Progo Yogyakarta. Program Studi Ilmu Keperawatan Sekolah Tinggi Ilmu
Kesehatan Aisyiyah Yogyakarta 2015. Diakses tanggal 10 Maret 2017

Sandyarman I, Hubungan Personal Hygiene Oleh Perawat Dengan Tingkat Kepuasan Pasien Imobilisasi Di Rumah Sakit Jember Klinik. Program Studi S1 Keperawatan Fakultas Ilmu Kesehatan Universitas Muhammadiyah Jember 2014. Diakses tanggal 11 Januari 2017

Suardana Ketut. 2007. Hubungan tingkat pemenuhan kebersihan diri dengan tingkatkepuasanpasienimobilisasi.Di akses tanggal 02 April 2017

Susanti Novi. 2013. Hubungan Karakteristik Perawat Dengan Motivasi Perawat Dalam PemenuhanKebutuhan Kebersihan DiriPasienDi Ruang Rawat Inap RSUDR.H.KoesnadiBondowoso. Diakses tanggal 10 Maret 2017 